\title{
Üst ekstremite iskelet traksiyonları (olekranon)
}

\author{
Upper extremity skeletal tractions (olecranon)
}

\author{
Tolga Atay \\ Süleyman Demirel Üniversitesi Tıp Fakültesi, Ortopedi ve Travmatoloji Anabilim Dalı, Isparta
}

\begin{abstract}
Azteklerden ve Antik Mısır'ılardan bugüne yaklaşık 3000 yıllık bir geçmişe sahip olan traksiyonlar, ortopedik travma tedavisinde gelişen teknolojiye rağmen halen yerini korumaktadır. Günümüzde en çok alt ekstremite travma cerrahisinde uygulanmasına rağmen, çok az oranda üst ekstremitede de kullanılmaktadır. Bu yazımızda, unutulmaya başlayan üst ekstremite iskelet traksiyonlarını hatırlatmaya çalışacağız.
\end{abstract}

Anahtar sözcükler: üst ekstremite; kırık; iskelet traksiyonu
From Aztecs and Ancient Egypt, tractions, which have a history of about 3000 years today, are still in place despite technological advances in the treatment of orthopedic trauma. Today, although the lower extremity is most commonly used in trauma surgery, it is also used in the upper extremity. In this review, we will try to remind you of the upper limb skeletal tractions that have been forgotten since.

Key words: upper extremity; fracture; skeletal traction

en başta gelen, hastanın hastanede kalış süresinin çok uzun olmasıdır. Buna paralel olarak da hastane maliyetleri çok yüksektir. Hastanın uzun süre yatmasından dolayı DVT (derin ven trombozu), PE (pulmoner emboli), bası yaraları ve pnömoni gibi komplikasyonlar görülebilir. Hastalara erken hareket verilememesi eklemlerde kontraktürlere neden olabilir. ${ }^{[3]}$

Üst ekstremitede uygulanan iskelet traksiyonları, genellikle koma halindeki hastalarda, multipl yaralanması olup cerrahinin yapılamadığı durumlarda tercih edilmektedir. Diğer traksiyonlarda olduğu gibi uzun yatak istirahati gerektirir.

\section{OLEKRANON PIN TRAKSIYON}

Pin (1,25 inch), olekranonun distal tip'ine yerleştirilir. Hastanın kolu baş üstünde olacak şekilde, dirsek $90^{\circ}$ fleksiyonda tutulur. Önkol ise yukarıdan gönderilen bir destekle sabitlenir. Pini gönderirken ulnar sinir yaralanması konusunda dikkatli olunmalıdır. Olekranon pin traksiyon, daha çok suprakondiler/distal humerus kırıklarında tercih edilmektedir. Traksiyon sırasında açısal ve rotasyonel düzeltmeler yapılabilir. Olekranonun kemik yapısından dolayı yeterince kuvvetli traksiyon uygulanabilir (Şekil 1 ve 2).

- Illetişim adresi: Prof. Dr. Tolga Atay, Süleyman Demirel Üniversitesi Tıp Fakültesi Ortopedi ve Travmatoloji Anabilim Dalı, Isparta Tel: 0532 - 4400099 e-posta: ataytolga@gmail.com

- Geliş tarihi: 1 Ağustos 2018 Kabul tarihi: 1 Ağustos 2018 


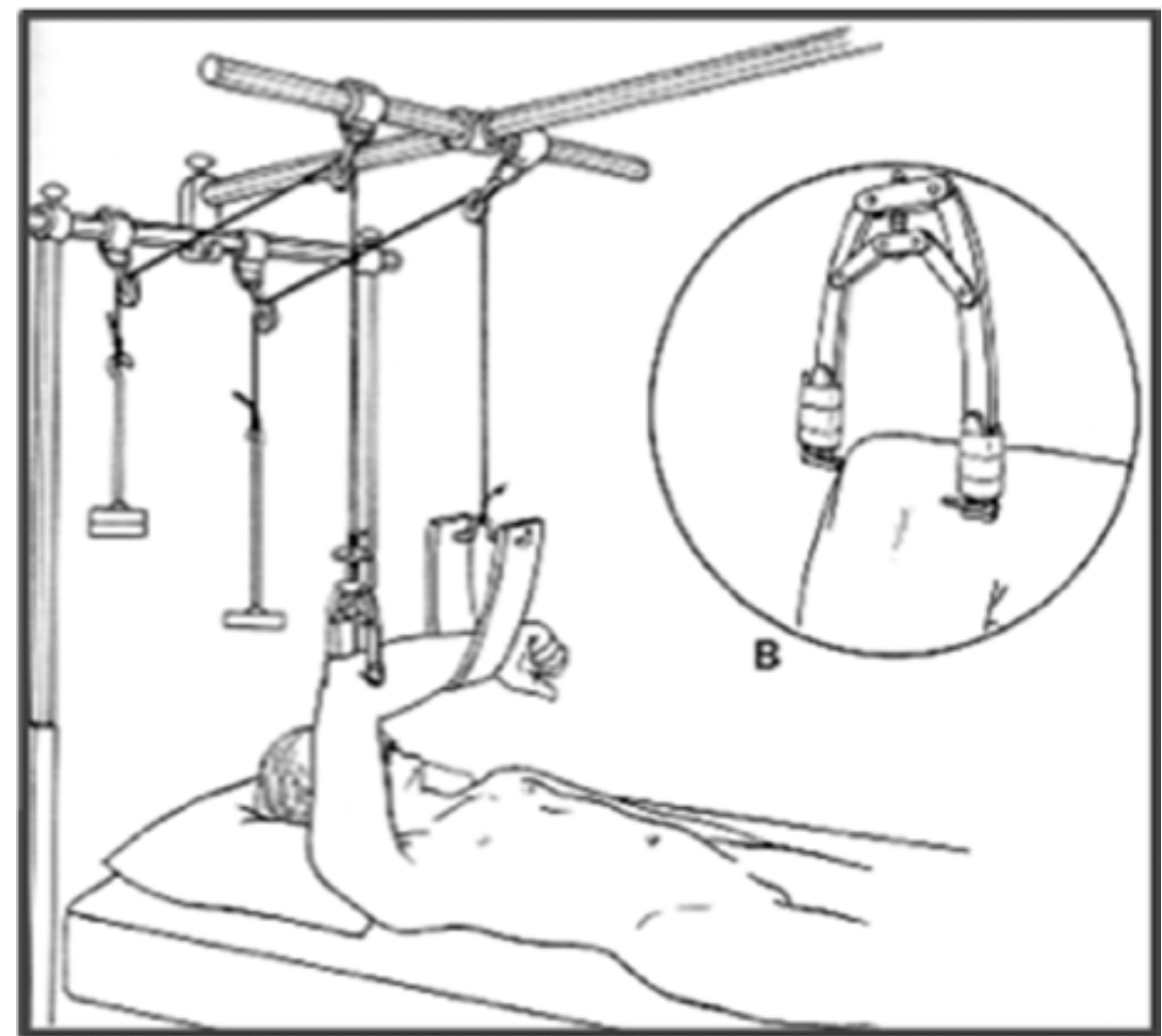

Şekil 1. Olekranon pin traksiyon.

(Kaynak: https://www.slideshare.net/OkaRahaditya/traction-in-orthopaedic)

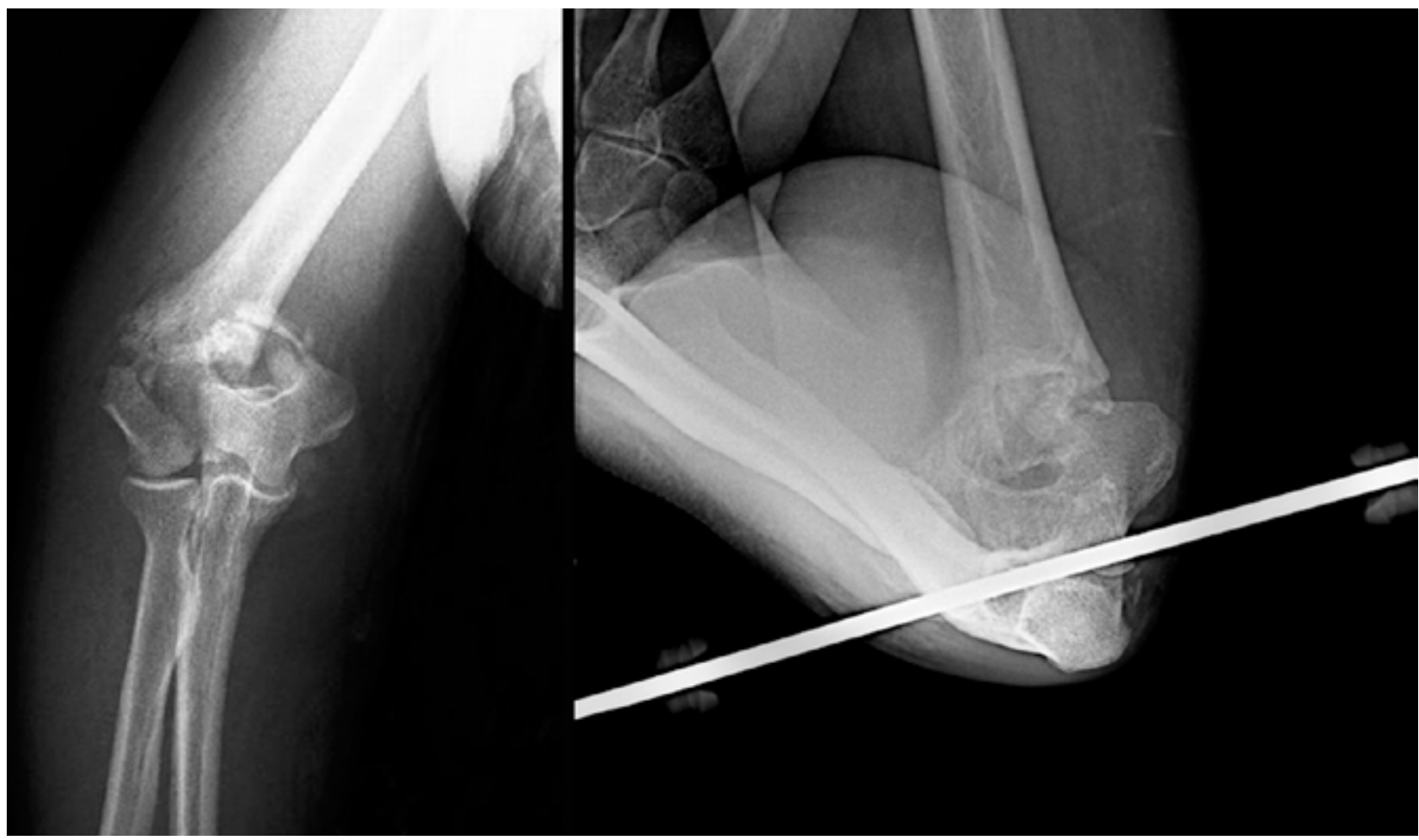

Şekil 2. Genel durumundan dolayı uzun süre cerrahiye alınamayacağı için yoğun bakım şartlarında uyguladığımız olekranon iskelet traksiyonlu bir olgumuz. 


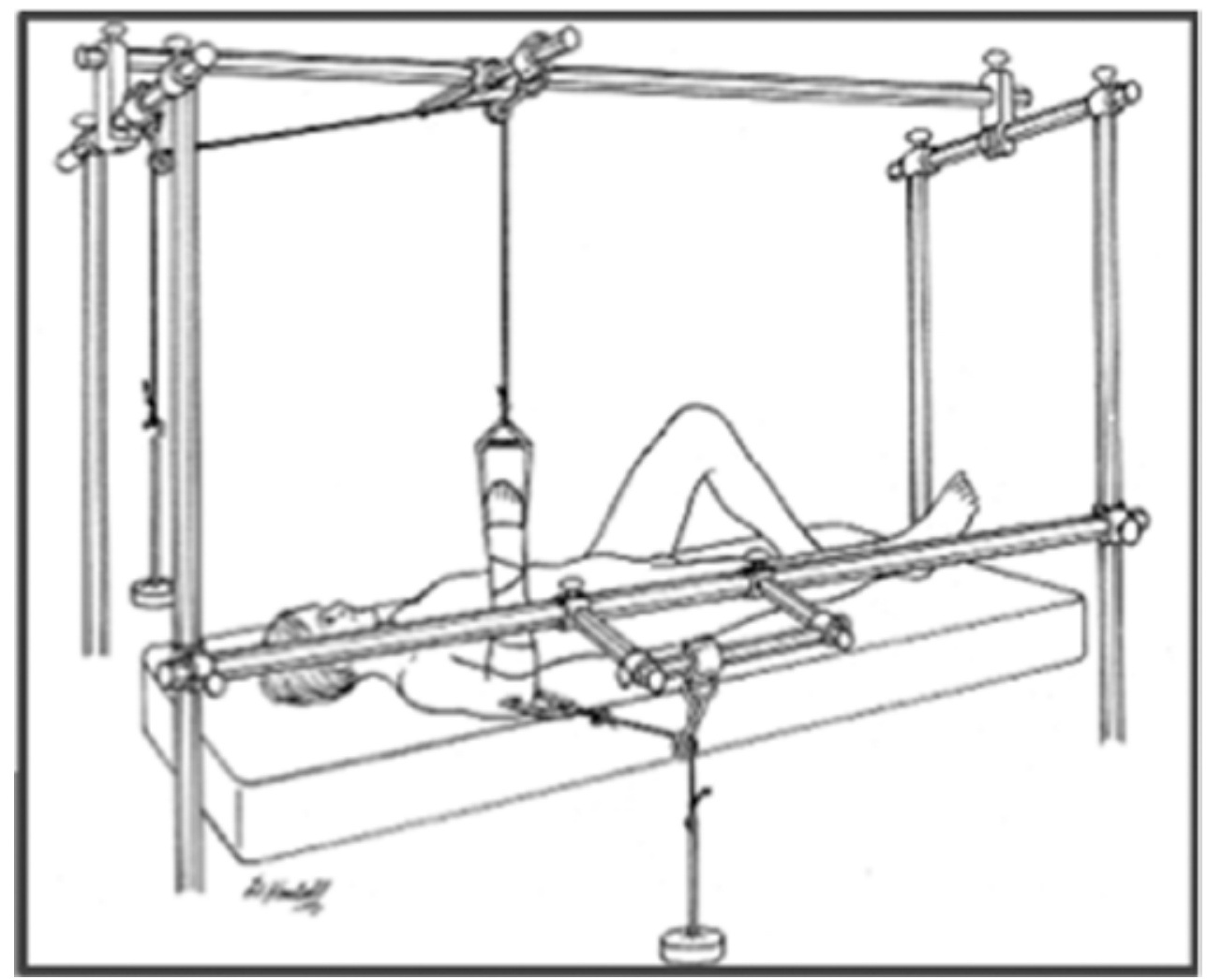

Şekil 3. Lateral olekranon traksiyon.

(Kaynak: https://www.slideshare.net/OkaRahaditya/traction-in-orthopaedic)

\section{LATERAL OLEKRANON TRAKSIYON}

Humerus kırıklarında kullanır. Hastanın kolu orta düzeyde abduksiyonda iken, olekranondan gönderilen pin vasıtasıyla lateral traksiyon uygulanır. Bu arada dirsek $90^{\circ}$ fleksiyona getirilir ve önkol cilt traksiyonu ile yukarıdan desteklenir (Şekil 3).

Olekranon iskelet traksiyon için pin gönderirken, öncelikle pin için giriş yerini tespit etmeliyiz. Skopi altında hastanın dirseğinin tam yan grafisini çektikten sonra, olekranon tip'ten $3 \mathrm{~cm}$ distaline mediyalden laterale doğru, ulnanın uzun aksına $90^{\circ}$ açıyla gönderilir. Bu şekilde, hem ulnar sinirin hem de açık epifizlerin yaralanmasından korunmuş olunur.

\section{KOMPLIKASYONLAR}

İskelet traksiyonları uygulamaları sırasında en çok korkulan komplikasyonlardan biri de sinir hasarıdır. Yukarıda bahsedildiği gibi, uygun teknikle uygulandığında bu risk en aza indirilir. İskelet traksiyonu uygulanacak bölgede epifizyel büyüme plağının olup olmadığına bakılmalıdır; aksi takdirde hasar oluşabilir. Traksiyon sonrasında kontroller yapılmadığı takdirde, malunion ve deformite oluşabilir. Aşırı yük verme ile bağ hasarının oluşabileceği de unutulmamalıdır. Nadir de olsa, uygun septik şartlar sağlanmadığı takdirde kemik içi enfeksiyonlar hatta osteomiyelitle karşılaşabiliriz. ${ }^{[4]}$

\section{KAYNAKLAR}

1. Flynn S. History of Traction. Int J Orthop Trauma Nurs 2018;28:4-7. Crossref

2. Abzug JM, Herman MJ. Management of supracondylar humerus fractures in children: current concepts. J Am Acad Orthop Surg 2012;20(2):69-77. Crossref

3. Skaggs DL, Flynn JM, Supracondylar Fractures of the Distal Humerus. In: Beaty JH, Kasser JR, editors. Rockwood and Wilkins' Fractures in Children, 5th ed. Philadelphia, PA: Lippincott Williams \& Wilkins; 2010. p.487-582.

4. Pountos I, Newman K, Giannoudis P. V. Instruments Used in Fracture Reduction. In: Giannoudis PV, editor. Fracture Reduction and Fixation Techniques -Upper Extremities. Springer International Publishing;2018. Crossref 